\title{
Learning transfer: the views of practitioners in Ireland
}

\author{
Paul Donovan and David P. Darcy
}

\begin{abstract}
Considerable expenditure on human resource development (HRD) has not necessarily resulted in a significant impact on organizational performance, and research suggests that the failure to transfer learning may be an important explanation. The search for factors affecting transfer has been extensive, as shown in Grossman and Salas's article in this issue, but, as they also show, more research is needed. The purpose of the present study is to ascertain the views of HRD practitioners (in Ireland) about the factors that they believe are relevant to the transfer of learning in the workplace. The aim is to discover whether practitioners have identified potential factors which researchers have not explored or not explored sufficiently. This group of practitioners was chosen because of the considerable control they wield over significant tranches of organizational resources. The method first involved engagement with 28 senior HRD practitioners in a workshop setting to create a transfer inventory based on their expert opinion. The initial inventory was then responded to online by a group of 314 practitioners indicating the relevance of the items to the question of transfer. Factor analysis was used to achieve parsimony among items, and 21 potential factors were identified. This study focused on the 15 factors adjudged by practitioners to be most relevant. It is concluded that trainer effectiveness, organizational linkage and training event climate, all deemed relevant by practitioners, may justify further research.
\end{abstract}

\section{Introduction}

The ultimate objective of human resource development (HRD) is to produce desirable behavioural and/or organizational change through learning (Al-Khayyat \& Eigamal, 1997). Indeed, HRD consumes significant resources; for example, it has been calculated that organizations in the United States invest between US\$53bn and US\$200bn

$\checkmark$ Paul Donovan, Director of Teaching and Learning, School of Business and Law National University of Ireland, Maynooth, Co. Kildare, Ireland. Email: paul.donovan@nuim.ie. David P. Darcy, Senior specialist, Irish Management Institute, Sandyford, Dublin 16, Ireland. Email: david.darcy@imi.ie 
annually in training (Bassi \& Van Buren, 1999), and in 2002 alone, US employers invested 2.2 percent of payroll in training (Sugrue, 2003). However, HRD has not delivered to organizations the kind of returns they might expect either materially or in terms of improved skills of the workforce (Barrett \& O'Connell, 2001; Cromwell \& Kolb, 2004). Several authors report poor transfer of learning from training applications back into the workplace (Baldwin \& Ford, 1988; Broad \& Newstrom, 1992; Facteau et al., 1995; Kaufman, 2002). Some research suggests that only 40 percent of content transfers immediately following a training intervention, and this figure falls to 25 percent after 6 months and to 15 percent after 1 year (Wexley \& Latham, 2007).

There has been extensive research identifying factors that affect transfer of learning. However, it has been suggested that further factors may exist (Colquitt et al., 2000; Gaudine \& Salks, 2004; Kontoghiorghes, 2004; Subedi, 2006; Yamnill \& McLean, 2001). Yamnill and McLean (2001) suggest that more research is required because transfer factors have not yet been widely studied with large populations and across very different settings. Chiaburu et al. agree, suggesting an expansion of the 'nomological net' to include constructs not heretofore examined (Chiaburu \& Marinova, 2005). The views of stakeholders that are under-represented in the literature may also be of value. Practitioners make financial and developmental decisions with regard to learning. Given the extent of resources expended globally on HRD, it is important to understand what factors are deemed more relevant for those decisions and how this understanding may inform the research agenda. The purpose of this study is to gather the views of practitioners, under-represented in the literature, on the factors that influence the transfer of learning.

Much of the research into transfer of learning, to date, has also been focused on the North American context (Van der Klink et al., 2001). As a result, the body of work on transfer may be culture specific, and Hofstede's seminal work on culture suggests that this factor is a significant differentiator in organizational behaviour across the globe (Hofstede, 2001). Other results suggest that culture will differentially impact the importance of various transfer factors (Subedi, 2006). In support of this, such calls could be answered through studies on transfer which are situated outside of the United States.

The next section outlines the theoretical development in evaluation from its inception to briefly describing subsequent evolutions and continuing up to and including the more recent focus on broadening the model to consider the organization. The research design section describes how we set about eliciting the views of practitioners in Ireland, including the use of an expert group for instrument creation and a broader group for instrument development. The results section specifies the evidence we uncovered including the identification of factors relevant to the practitioners. Finally, the discussion section evaluates these factors, considers the limitations of the present study and suggests avenues for future research.

\section{Literature review}

This section outlines the development of research into evaluation of HRD from its original atheoretical stage in the middle of the last century, e.g. Kirkpatrick, (1959a,b) to the more comprehensive and systemic approaches such as Colquitt et al. (2000) and Kontoghiorghes (2004) of later years. The original literature focused mainly on the outcomes of the training intervention, whereas the later approaches introduce the element of context. Finally, we discuss recent work that touches on practitioner perspectives on transfer.

The most popular and most enduring contribution to the field of HRD evaluation has been shown to be the model developed by Kirkpatrick in a series of four articles for the American Society of Training and Development Journal (Kirkpatrick, 1959a,b, 1960a,b). Perhaps because of its simplicity and ease of understanding, it has become the most widely known and accepted approach to the subject among practitioners (Alliger \& Janak, 1989; Bates \& Holton, 2004; Salas \& Cannon-Bowers, 2001). This model is not without its critics partly due to its focus on outcomes and its lack of consideration for the variables that affect these outcomes (Holton, 1996). Subsequent research has 
examined these factors, especially those relating to the system and climate surrounding the training intervention. This introduction of context has significantly enhanced the Kirkpatrick approach to evaluation (Baldwin \& Ford, 1988; Broad \& Newstrom, 1992; Colquitt et al., 2000; Holton, 1996) and has greatly improved its applicability.

Baldwin and Ford (1988) suggested that transfer had become a major issue in organizational training and that despite significant investment in training ( $\$ 100$ billion annually then), not more than 10 percent of these expenditures actually resulted in transfer to the job. They identify three domains that affect the transfer from a training intervention back into the workplace, notably: trainee characteristics, training design and work environment. Trainee characteristics include individual elements such as ability, personality and motivation. Training design refers to the relationship between the activities engaged in on the training programme and the actual job requirements of the trainee. Work environment is concerned with the degree to which the trainee has the opportunity to use and practice what has been learned in training.

Whereas the (Baldwin \& Ford, 1988) model of transfer concludes with the maintenance and generalization of learning, subsequent models carried on to describe the impact of learning on individual and organizational performance (such as Yamnill \& McLean, 2001). Earlier approaches to the transfer of training perceived it as a direct link between training and behaviour (Yamnill \& McLean, 2001). However, the purpose of training and development is to improve the performance of the organization and the individual (Torraco \& Swanson, 1995). Unless learning is transferred back into the workplace in the form of effective performance, it is of little value to organizations (Bates et al., 2000).

More recent research into transfer has continued to highlight the importance of context in terms of the work environment for the transfer of training (Alvarez et al., 2004; Cheng, 2000; Ford \& Weissbein, 1997; Holton et al., 2003; Tannenbaum \& Yukl, 1992). However, there continues to be a lack of consensus on the nomological network of factors affecting the transfer of training back to the workplace (Chiaburu \& Tekleab, 2005; Holton et al., 2000).

Accordingly, Holton et al. (2000) proposed the Learning Transfer System Inventory (LTSI) as a measure of 16 transfer climate dimensions: perceived content validity, transfer design, opportunity to use learning, personal capacity for transfer, motivation to transfer learning, transfer effort-performance expectancies, performance-outcome expectancies, supervisor/manager support, supervisor/manager sanctions, peer support, openness to change, positive personal outcomes, negative personal outcomes, supervisor feedback/performance coaching, learner readiness and performance selfefficacy. The authors make significant claims for the LTSI stating that it assesses 'all factors in the person, training, and organization that influence the transfer of learning to job performance' (Holton et al., 2000, pp. 335-6). Noe (2000) suggests that the inventory is incomplete as it does not adequately measure principles of learning, sequencing and training content. Holton et al. further claim that although diagnosis of the transfer climate is important, 'to date, no tool has emerged to conduct such diagnosis' (Holton et al., 2000, p. 334). Holton was not, however, alone in developing a model to describe transfer of learning.

Colquitt et al. (2000) provide an integrative module of motivation to transfer learning shown in Figure 1. This model includes a description of the relationship of personality, situational and job-career variables on the motivation to learn which consequently affects learning and, ultimately, transfer.

The General Training Climate Scale (GTCS) is a three-factor transfer model including managerial support, job support and organizational support, and it provides a useful conceptualization of the transfer climate construct (Tracey \& Tews, 2005). However, its authors admit that due to deficiencies in research procedures (lack of opportunity for subject matter experts to add items to the scale), the transfer climate domain may not be fully captured. The introduction of new organizational elements such as continuous learning brings a more systemic approach to the GTCS than previous measures. Further research is needed to identify additional factors involved in the transfer of training that are, as yet, undiscovered. 


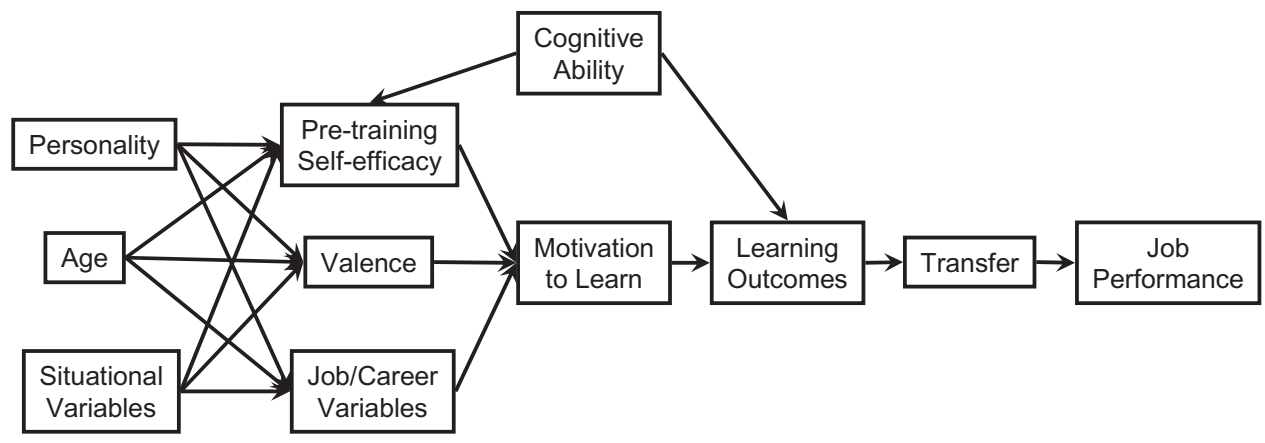

Figure 1: Integrative model of motivation to transfer training, adapted from Colquitt et al. (2000).

The extant transfer of learning approaches relies on existing models from the literature (Kontoghiorghes, 2004). Using expectancy theory from Vroom (1964) in the transfer of training, we can suggest that trainees will be motivated to attend and learn from training programmes if certain expectations or beliefs are present. These beliefs are: (1) that their efforts will result in learning the new skills or information; (2) that by attending the programmes and learning new skills, they will increase their job performance; (3) that doing so will help them obtain desired outcomes or prevent unwanted outcomes (De Simone et al., 2002). Thus, pre-training motivation is strongly related to effective transfer of learning (Chiaburu \& Lindsay, 2008; Chiaburu \& Marinova, 2005; Green \& Skinner, 2005).

Kontoghiorghes (2004) further suggests that the existing transfer research pertains to trainee characteristics or elements which are directly related to the training context or training-related outcomes. The implications of this criticism are that the transfer factors that have been identified, to date, do not provide enough grasp of the entire spectrum of influences on transfer as existing research concentrates mainly on the immediate context of the training initiative. Thus, training is being described as a 'non systemic phenomenon' (Kontoghiorghes, 2004, p. 211). By focusing only on climate, in this restricted sense, previous research has neglected important factors which affect the belief of trainees that training can actually result in performance.

Others have broadened the search for transfer factors by describing a wider net of factors and the transfer system that also comprises the transfer climate within it (Kontoghiorghes, 2004). However, it is ironic that authors who propose the transfer system as a more holistic way of considering evaluation of a training intervention may also inadvertently be ignoring the systemic nature of what they study.

The search for this more holistic model has led to a conceptual framework of training transfer to encompass these expanded work environment factors (Kontoghiorghes, 2004). The model presented in Figure 2 provides a view of the learning transfer process that is broadly inclusive of the previous work on transfer. It suggests individual and organizational performance as the common link between learning transfer and work environment characteristics. It also suggests that the work environment is a very important element in learning transfer (Kontoghiorghes, 2004). The more the trainee believes that the work environment is conducive to high performance, the more the trainee will believe that his or her efforts will result in an attainable and desirable outcome (Kontoghiorghes, 2004).

This model can be contrasted with traditional approaches to transfer that, to a large degree, ignore the systemic factors that affect the transfer of training. Transfer can only be understood and predicted by examining the entire system of influences (Ruona et al., 2002). The concentration on trainee characteristics and attributes which are directly related to the training context or training-related outcomes suggests that training is viewed as a non-systemic process. Some variables which affect performance are 


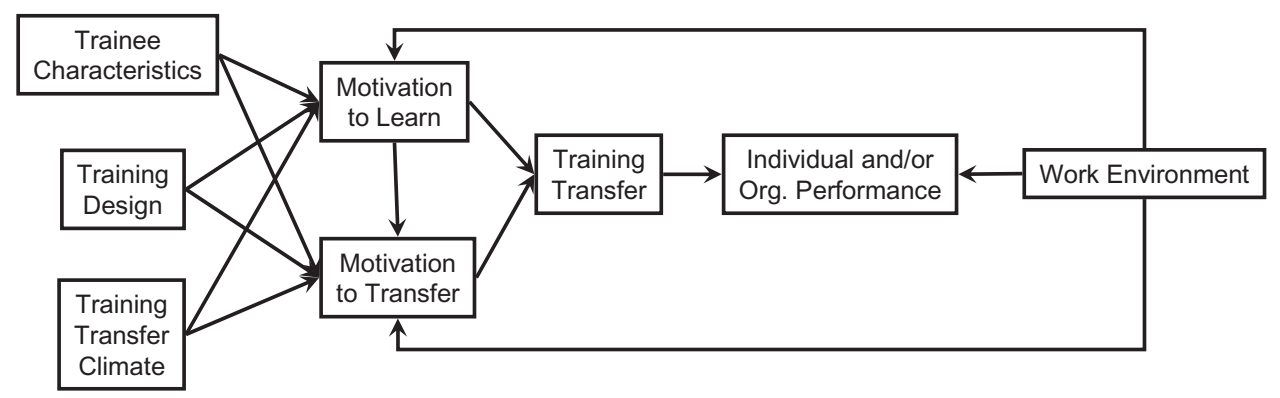

Figure 2: Systemic model of training transfer, adapted from Kontoghiorghes (2004).

missing from the traditional approaches to transfer. In addition to these factors, there is a need to review systemic issues in the search for transfer effectiveness.

Yamnill and McLean agree and appeal for such research, suggesting that what is needed is 'an examination of systems wide components that determine whether a training program can yield meaningful change ... and ... an examination of contextual constraints and barriers that trainees face in applying learning in the workplace' (Yamnill \& McLean, 2001, p. 206). The need for attention to the organizational context in researching transfer has gained broad support (Gaudine \& Salks, 2004). This is supported by Colquitt et al. who bemoan that the examination of situational characteristics remains surprisingly rare' (Colquitt et al., 2000, p. 700). This regard for context is, significantly, absent from the practitioner literature which has focused principally on outcomes (Kirkpatrick, 1994). This divergence in focus between practice and theory is a principal stimulus for this current research.

Despite these debates concerning the relevance of various factors of transfer, it is likely that these factors may vary according to context. Geographical and other context elements such as the business sector may play a role in deciding which of these factors influence the transfer of learning and to what degree. Our research objective, therefore, was to explore what factors those in the field of practice believe are most relevant to the transfer of learning back to the workplace. In doing so, we may usefully inform the research agenda.

\section{Research design}

The research was conducted in the Irish Management Institute (IMI), an executive education institution in the Republic of Ireland. The decision to locate the research in Ireland was, in part, one of convenience. However, there have been calls in the literature for research to be conducted outside of North America (Van der Klink et al., 2001). This research therefore enables researchers and practitioners to compare and contrast transfer factors in different settings, something that is, however, outside the scope of this study. This research, which is exploratory in nature, is designed to establish the views of practice rather than contrast views from various stakeholder groups, although a preliminary comparison is made between the factors derived from the perspective of practice and those in the literature.

For the practitioners' view to emerge as unrestricted as possible, a decision was made to create and rate an original inventory. In order to rigorously generate the relevant constructs, the research was executed in two phases. In the first phase, 28 senior HRD executives participated in a half-day workshop to unearth items relevant to training transfer. The workshop generated an inventory of 103 items. During the second phase, an online instrument was developed and was responded to by 314 HRD professionals. Their responses were factor analysed for parsimony, and the final set of factors was categorized. This method on transfer research had been used in the past (Kontoghiorghes, 2001). Similar to Hutchins and Burke (2007), the factors were then 
examined to see how the identified factors were rated in terms of their relevance. Finally, the set of relevant factors was compared to those suggested by the literature.

\section{Phase 1: Instrument creation through expert workshop}

A letter of invitation was sent to potential workshop participants. The invitees were drawn from the IMI's database of 1600 organizations in Ireland. Two hundred organizations were randomly selected from the database, and 28 participated in the workshop at the IMI. Within each organization selected, the individual with the most senior HRD role was selected. Such an individual would be in decision-making roles and have control over budgets which may be used to purchase training programmes from IMI, and they would be relatively senior in rank. Evidence for the experience accessed through the workshop can be seen in the range of participant titles including HRD director, HRD manager, learning and development manager, training manager, training and development manager, training director and director of development. No data were collected on ethnic origin; however, an inspection of surname data revealed that respondents were principally of Irish ethnic origin.

At the commencement of the workshop, participants were given a description of the proposed research. The question considered by the workshop participants was: 'What factors affect the transfer of training from the intervention back into the workplace'? Four teams, each of seven participants, developed items. From discussion during and follow-up after the workshop, an inventory was produced comprising 103 items. Each item of the inventory was written in the form of an assertion as an aid to clarity and to prepare for its dissemination, e.g. 'I am motivated to use this new learning in my job'.

\section{Phase 2: Online item relevance assessment by HRD professionals}

To assess practitioners' views of the generated instrument, a wider audience of general HRD professionals was sought. Specifically, to increase viability of applying a factor analysis to produce interpretable factors, a target of more than 300 respondents is suggested (Gorusch, 1997). Assuming a response rate of 15 percent common in such research, the sample pool should therefore include 2000 potential respondents. The aforementioned IMI database includes 1600 potential responding organizations. To this was added the membership organizations of the Irish Institute of Training and Development. This added the needed 400 (non-redundant) potential responding organizations to the set. Within each organization, a general HRD professional was identified and an email invitation to participate (and one reminder) was issued to that individual. The inventory was prepared for an online survey (http:/ / www.freesurveyonline.com) and the invitation included the survey's URL. Three hundred fourteen responded for an actual response rate of 15.7 percent.

The instrument asked the question: 'How relevant you think the statement is to the transfer of learning from training events to the job in your organization'. The instrument utilized a five-point Likert scale that included the responses of 'very relevant', 'relevant', 'neither relevant nor irrelevant', 'irrelevant' and 'very irrelevant'. The responses were factor analysed to increase parsimony and extract the latent factor structure. The preliminary structure was further refined with reference to component items and provided factor titles. The factors were then analysed in terms of relevance as rated by the profession. The results can be seen in the next section.

\section{Results}

Factor analysis led to the identification of 21 factors. Of those 21,15 were rated as relevant by the HRD professionals. A comparison of the 15 factors (and, indeed, the 6 rated as less relevant) with factors suggested by the literature reveals interesting patterns. 


\section{Respondent demographics}

Demographics for the 314 respondents and their respective organizations to the online survey are described in Tables 1-6.

\section{Exploratory factor analysis}

In preliminary analysis, inspection of the correlation matrix revealed the presence of many coefficients of 0.3 and above. From the factor analysis, the Kaiser-Meyer-Oklin value was 0.91, exceeding the recommended criterion of 0.6 (Kaiser, 1970, 1974). Bartlett's test of sphericity (Bartlett, 1954) was significant $(p=0.000)$, supporting the factorability of the correlation matrix.

Principal components analysis revealed the presence of 23 components with eigenvalues exceeding 1, explaining 70.15 percent of the variance cumulatively. An inspection of the scree plot did not reveal a clean break (Catell, 1966). It was thus decided to retain all 23 components for further analysis. To aid the interpretation of

Table 1: Respondent profile by job category $(\mathrm{n}=314)$

Job category

$\%$ of respondents

Learning and development

$21 \%$

Training

$45 \%$

HRD

$4 \%$

HR

$19 \%$

Other

$11 \%$

Table 2: Respondent profile by hierarchical level $(\mathrm{n}=314)$

Hierarchical level

$\%$ of respondents

\begin{tabular}{lc}
\hline Managerial & $55 \%$ \\
Specialist & $37 \%$ \\
Administrative & $8 \%$ \\
\hline
\end{tabular}

Table 3: Respondent profile by sector $(\mathrm{n}=314)$

Sector

$\%$ of respondents

Financial services

$12 \%$

Manufacturing

$26 \%$

Public sector

$26 \%$

Services

$24 \%$

Other

$12 \%$

Table 4: Respondent organization profile by number of employees $(\mathrm{n}=314)$

Number of employees

50 employees or fewer

51 to 250 employees

251 to 1000 employees

1001 to 5000 employees
$\%$ of respondents 
Tenure in organization $\%$ of respondents

Less than 1 year $14 \%$

Between 1 and 5 years $51 \%$

Between 6 and 10 years $22 \%$ More than 10 years

Table 6: Respondent profile by tenure in current post $(\mathrm{n}=314)$

Tenure in post $\%$ of respondents

Less than 1 year $9 \%$

Between 1 and 5 years $40 \%$

Between 6 and 10 years $27 \%$ More than 10 years

these components, varimax rotation was performed. The rotated solution revealed the presence of simple structure (Thurstone, 1947) with all components showing a number of strong loadings (Fabrigar et al., 1999).

One of the objectives of using principal components analysis is to achieve parsimony in the number of items, perhaps reducing the overall inventory (Stevens, 2002). It is common practice to retain items that load most highly and beyond a certain criterion, often 0.40 (Gorusch, 1997), although Stevens (2002) reports the minimum significant loading to be $|0.298|$. In order to maintain a reasonable balance between detection of coherent factors and cross loadings, it was decided to retain items that yielded factor loadings of above 0.50 . The rotated solution revealed the same simple structure with all components showing a number of strong loadings. All items with a cross loading greater than 0.5 loaded on only one factor. One factor (factor 23) was removed as it consisted entirely of cross loadings from items that were loaded on other factors.

The factors were further examined for theoretical parsimony and to name them. In particular, we used the models and factors detailed in the theoretical background to understand and label the factors that we had derived from the factor analysis. One factor (factor 12 from the original 23, containing two items) had no theoretical meaning and it was deleted. Some of the factors had only one or two items loading on them. Such factors are usually described as being 'poorly defined' and interpretation of such factors can be hazardous (Tabachnick \& Fidell, 2001). However, given the exploratory nature of this research, it was decided to retain all factors due to the interesting possibilities that they presented for the research; such practice is common in exploratory factor analysis. This left 70 items distributed among 21 factors as can be seen in Table 7 .

The table includes factor titles, a representative item for each factor, the number of items constituting the factor and factor reliabilities (measured by Cronbach's alpha). Factors are numbered from 1 to 21 in terms of the order in which they emerged from the principal components analysis. Although most of the factors are highly reliable with alpha scores greater than 0.7 , some are less; all of those with alpha scores of less than 0.7 are two-item factors that were found to have sufficient theoretical merit to continue using. The complete item loadings are reproduced in Appendix 1.

\section{Assessing factor relevance}

Table 8 provides the factor relevance scores, ordered in terms of those rated most relevant first, with 5 representing highly relevant. The relevance scores in Table 8 were calculated using arithmetic means from items in each factor. A natural break can be 
Table 7: Factors and items emerging from factor analysis

\begin{tabular}{|c|c|c|c|c|}
\hline No. & Factor & Items & Representative item & Loading \\
\hline 1 & $\begin{array}{l}\text { Learning transfer } \\
\text { management }\end{array}$ & 19 & $\begin{array}{l}\text { My manager prepared me } \\
\text { for this training }\end{array}$ & 0.96 \\
\hline 2 & Peer support & 6 & $\begin{array}{l}\text { My colleagues support me in } \\
\text { the use of new skills } \\
\text { learned in training }\end{array}$ & 0.87 \\
\hline 3 & Perceived relevance & 4 & $\begin{array}{l}\text { I can see the relevance of this } \\
\text { training for my job }\end{array}$ & 0.72 \\
\hline 4 & Trainer effectiveness & 5 & $\begin{array}{l}\text { The trainer provided good } \\
\text { feedback }\end{array}$ & 0.89 \\
\hline 5 & $\begin{array}{l}\text { Organizational support for } \\
\text { learning }\end{array}$ & 4 & $\begin{array}{l}\text { Training is valued in my } \\
\text { organization }\end{array}$ & 0.89 \\
\hline 6 & Job autonomy & 2 & $\begin{array}{l}\text { I have a lot of freedom in the } \\
\text { way I do my work }\end{array}$ & 0.60 \\
\hline 7 & Quality focus & 3 & $\begin{array}{l}\text { There is a commitment to } \\
\text { excellence in my } \\
\text { organization }\end{array}$ & 0.79 \\
\hline 8 & Opportunity to use & 5 & $\begin{array}{l}\text { I'm under too much pressure } \\
\text { to apply this learning }\end{array}$ & 0.77 \\
\hline 9 & Career utility & 3 & $\begin{array}{l}\text { I can see how this training } \\
\text { will enhance my career }\end{array}$ & 0.77 \\
\hline 10 & Job design & 3 & $\begin{array}{l}\text { My job requires a range of } \\
\text { talents and abilities }\end{array}$ & 0.80 \\
\hline 11 & Organizational structure & 1 & $\begin{array}{l}\text { My organization has a flat } \\
\text { hierarchical structure }\end{array}$ & $\mathrm{n} / \mathrm{a}$ \\
\hline 12 & Training event climate & 2 & $\begin{array}{l}\text { This group of participants } \\
\text { worked well together }\end{array}$ & 0.81 \\
\hline 13 & Individual rewards & 2 & $\begin{array}{l}\text { This training will enhance } \\
\text { my earning potential }\end{array}$ & 0.72 \\
\hline 14 & Organizational linkage & 2 & $\begin{array}{l}\text { This training is driven by } \\
\text { important changes in my } \\
\text { organization }\end{array}$ & 0.68 \\
\hline 15 & Management expectation & 2 & $\begin{array}{l}\text { My manager was responsible } \\
\text { for deciding on this } \\
\text { training }\end{array}$ & 0.56 \\
\hline 16 & Location of training function & 2 & $\begin{array}{l}\text { The training function is run } \\
\text { by an internal department } \\
\text { in my organization }\end{array}$ & -0.72 \\
\hline 17 & Clarity of individual's job & 1 & My job is clearly specified & $\mathrm{n} / \mathrm{a}$ \\
\hline 18 & $\begin{array}{l}\text { Training linked to job } \\
\text { purpose }\end{array}$ & 1 & $\begin{array}{l}\text { Training is always conducted } \\
\text { with a specific job purpose } \\
\text { in mind }\end{array}$ & $\mathrm{n} / \mathrm{a}$ \\
\hline 19 & Motivation to attend & 1 & $\begin{array}{l}\text { This training is something I } \\
\text { have looked for }\end{array}$ & $\mathrm{n} / \mathrm{a}$ \\
\hline 20 & $\begin{array}{l}\text { Decentralization of training } \\
\text { function }\end{array}$ & 1 & $\begin{array}{l}\text { The training function resides } \\
\text { within each department in } \\
\text { my company }\end{array}$ & $\mathrm{n} / \mathrm{a}$ \\
\hline 21 & $\begin{array}{l}\text { Trainer understanding of } \\
\text { context }\end{array}$ & 1 & $\begin{array}{l}\text { The trainer understood what } \\
\text { I do at work }\end{array}$ & $\mathrm{n} / \mathrm{a}$ \\
\hline
\end{tabular}


Table 8: Factor relevance rating, highest relevance listed first

\begin{tabular}{|c|c|c|c|c|c|c|}
\hline Factor & Title & $n$ & Min & Max & Mean & Std Dev \\
\hline 4 & Trainer effectiveness & 313 & 2.2 & 5 & 4.336 & 0.558 \\
\hline 3 & Perceived relevance & 314 & 2 & 5 & 4.162 & 0.554 \\
\hline 10 & Job design & 308 & 1.67 & 5 & 4.071 & 0.644 \\
\hline 5 & Organizational support for learning & 312 & 1 & 5 & 4.034 & 0.767 \\
\hline 19 & Motivation to attend & 311 & 1 & 5 & 4.019 & 0.823 \\
\hline 7 & Quality focus & 309 & 1 & 5 & 4.011 & 0.707 \\
\hline 12 & Training event climate & 311 & 1 & 5 & 3.950 & 0.716 \\
\hline 21 & Trainer understanding of context & 313 & 1 & 5 & 3.907 & 0.906 \\
\hline 6 & Job autonomy & 310 & 1.5 & 5 & 3.823 & 0.713 \\
\hline 17 & Clarity of individual's job & 306 & 1 & 5 & 3.801 & 0.960 \\
\hline 2 & Peer support & 312 & 1.33 & 5 & 3.787 & 0.635 \\
\hline 18 & Training linked to job purpose & 308 & 1 & 5 & 3.604 & 0.985 \\
\hline 9 & Career utility & 314 & 1 & 5 & 3.554 & 0.801 \\
\hline 14 & Organizational linkage & 314 & 1 & 5 & 3.525 & 0.791 \\
\hline 1 & Learning transfer management & 314 & 1.26 & 5 & 3.502 & 0.805 \\
\hline 15 & Management expectation & 312 & 1 & 5 & 3.120 & 0.908 \\
\hline 11 & Organizational structure & 306 & 1 & 5 & 3.098 & 1.042 \\
\hline 8 & Opportunity to use & 314 & 1 & 5 & 3.083 & 0.823 \\
\hline 16 & Location of training function & 309 & 1 & 5 & 2.972 & 0.672 \\
\hline 20 & Decentralization of training function & 308 & 1 & 5 & 2.860 & 1.117 \\
\hline 13 & Individual rewards & 314 & 1 & 5 & 2.705 & 1.019 \\
\hline
\end{tabular}

observed at 3.5, the point where the Likert scale altered from 'Neither Relevant Nor Irrelevant', scored at 4, to 'Relevant', scored at 3. There is also a natural disconnect in the form of a 0.4 gap between factor means at the point separating the top 15 factors from the bottom 6. Thus, the first 15 factors appear to play significant roles in decision making by practice, whereas the last six are deemed less relevant. We now examine each of the 15 factors deemed of greater relevance with a brief comment on the six deemed of less relevance.

The factor which had the highest mean rated by the profession is trainer effectiveness and consisted of five items that were related to the perceived effectiveness and activity of the trainer delivering the content. This factor comprised elements of preparation, commitment and relating the training content to the job needs of the learner. This construct is similar in some respects to trainer characteristics identified in previous literature. For example, trainer characteristics refers to 'knowledge of the subject matter, professional experience, and knowledge of learning style and teaching principles' (Burke \& Hutchins, 2008, p. 115). In other research, the role of the trainer is referred to under training design and includes activities and exercises used (Holton, 2005). Trainer effectiveness as elicited in this study comprises the following items:

- The trainer was well prepared

- The trainer was enthusiastic about the subject matter

- The trainer showed commitment to the goals of the training

- The trainer tried to relate the training content to my job needs

- The trainer provided good feedback

This construct includes some items detailed in previous research as well as some items not described in previous research, perhaps suggesting that the construct is underresearched and may merit further research attention.

Four items loaded on to the second factor, entitled perceived relevance, which is evocative of the existing construct of perceived content validity identified by Holton et al. (2000). Although similar to Holton's construct, it is also close to Clark et al. (1993) 
in their development of job utility. It differs slightly from this construct in that there is a motivational element in the participant's regard for the learning.

Job design was the factor which attracted the third highest ranking in the set. This component loaded three items referring mainly to the skills required to do the job and the significance of the job. These items are related to traditional job design issues. This construct has been recognized in previous transfer research (Kontoghiorghes, 2004).

Organizational support for learning attracted four items which were synonymous with the existence of a climate of learning in the organization. This construct is similar to that of organizational support which had previously been identified by Facteau et al. (1995) and Tracey and Tews (2005).

Motivation to attend came fifth in order of means of the factors from this research. This factor is similar motivation to learn, a well described construct in the transfer literature (Kontoghiorghes, 2002; Mathieu et al., 1993; Tracey et al., 1995). Only one item loaded on this slightly different construct which refers to the participants' desire to have the training.

Three items loaded on to a component which was labelled quality focus. This construct is analogous to quality management, a systemic concept described by Kontoghiorghes (2004).

Training event climate had the seventh highest mean. This was another of the components identified in the research which did not have obvious analogous constructs or items in the extant literature. Training event climate referred to the atmosphere which existed between participants on the intervention and included how participants worked together and shared information willingly. Only two items loaded on this factor as follows:

- This group of participants worked well together

- There was a free and useful exchange of information between participants in this training

Trainer understanding of context which was a single-item factor came eighth in the ranking of means. This construct refers to the level of understanding the trainer had of the workplace context of the learner. This factor, although not recorded in previous literature, seems intuitively appropriate to successful transfer of learning.

Two items loaded on to the next component which has been named job autonomy and this is somewhat similar to a broader construct of job design that was identified by Kontoghiorghes (2004). This may also be related to job involvement (Mathieu et al., 1992; Noe \& Schmitt, 1986).

Only one item loaded on to the next component which was labelled clarity of the individual's job. There are certain echoes of task cues here as identified in previous research (Rouiller \& Goldstein, 1993).

The eleventh component, in terms of mean, loaded six items and was labelled peer support. This seems analogous to the construct entitled co-worker support and peer support identified in previous literature (Chiaburu \& Marinova, 2005; Clark et al., 1993; Colquitt et al., 2000; Facteau et al., 1995; Holton et al., 2000).

Training linked to job purpose is a systemic factor which related to the cultural belief within the organization that training should always be linked to a job purpose. No identical constructs were found in the literature; however, this factor may be somewhat similar to the existing construct of perceived content validity identified by Holton et al. (2000).

Three items loaded on to the next component which has been named career utility. This is analogous to a similar construct of the same name describing the perceived usefulness of training in facilitating the attainment of job goals (Clark et al., 1993).

Two items loaded on to a further component which was entitled organizational linkage. This factor referred to organizational problems and important changes which were to be addressed by the training. The items which loaded on to this factor were:

- This training is driven by important changes in my organization

- This training will solve some of my organization's problems 
Some attention has been given to this general area in the literature (e.g. Lim \& Johnson, 2002; Montesino, 2002). However, the topic requires further research (Hutchins \& Burke, 2007).

Learning transfer management was listed as fifteenth in the set of factors identified. This construct is broadly analogous to supervisor support, the extent to which supervisors and managers support and reinforce the use of training on the job (Holton, 1996; Kontoghiorghes, 2001, 2002, 2004; Tharenou, 2001). However, learning transfer management is a much broader construct including preparation by the manager of the participant, supply of resources and opportunity to use resources to apply the learning. Therefore, it is not simply supervisor support but an organizational construct which speaks of managerial and organizational attention to, and management of, transfer.

The remaining factors followed a natural discontinuity in the rankings with means ranging from 3.1 down to 2.7 (see Table 8). These were: management expectation regarding whether or not the training was compulsory; organizational structure which referred to the flatness of the organizational hierarchy; the opportunity to use which means the opportunity the learner had to use the learning (Rouiller \& Goldstein, 1993); the location of the training function and decentralization of the training function referred to the location of the training function within the organization and the degree to which it was centralized or decentralized; individual rewards referred to the presence of financial incentives and outcomes for the learner for using the learning back at work. These relatively low means suggest that these factors were seen by the respondents as not being relevant to the transfer of learning.

\section{Discussion}

This research identified the key factors in the transfer of learning from training interventions according to HRD practitioners in Ireland. Twenty-one factors comprising of 70 items were identified from an exploratory factor analysis examining the factors relevant to the HRD practitioner. Of those factors, 15 were deemed relevant or highly relevant, whereas six were viewed as being less relevant.

\section{Limitations of the study}

Before discussing these results further, we specify limitations that may impact the generalizability of the results. In this exploratory factor analysis, some of the factors are of potentially questionable validity. Further research will be useful in expanding or deleting them. The degree to which the findings are attributable to national cultural factors is unclear to us. Validation across other cultures will enable examination of this issue. The HRD profession was well represented both by span and depth of experience of the field, as were a wide variety of industries and firm sizes. Despite the broad range of organization sectors and sizes, consideration of national culture could suggest differences between the set of factors identified by Irish HRD practitioners and those commonly applied in transfer research, for example Subedi (2006). Although the choice of dependent variable (relevance) could be construed as problematic, we believe that practice relies on the identified factors in their day-to-day operations of intervention choice and design.

The sample in this research is located in the geographical setting of Ireland. The sample comprised mainly Irish nationals, selected from what was, and still is, a predominantly indigenous population. The sample, like many others in social science research, is a convenience one. The location and the sample make-up provide a response to the calls from other researchers for transfer studies to be made in locations other than the North American one (Van der Klink et al., 2001). The research thus provides an interesting comparison site to contrast Irish and European practitioner views on transfer with those contained within the mainly American literature.

\section{Contribution of the study}

Many of the factors identified in this study by the practitioners as being relevant to transfer of learning are well understood in the literature. However, three factors 
identified here may be under-researched. Practitioners view the issue of trainer effectiveness as being the most highly relevant and suggested several dimensions not well represented by the extant literature. Given that the focus and concentration of the subjects of this paper, the practitioners, is contact with and management of the operational trainer, this result may be unsurprising. Nonetheless, there is evidence here to suggest that further research into this construct may be rewarding.

Two further factors, organizational linkage and training event climate, were identified by practitioners as being relevant to the transfer of learning. Exploration of the items loading on these constructs suggested that they may be not well researched. However, given that each of these constructs loaded only two factors, we are cautious regarding their interpretation.

In this current study, individual rewards is seen as least relevant by practitioners and yet it is central in the literature on transfer of learning (Holton, 1996; Kontoghiorghes, 2004). Although counter-intuitive, practitioners may conclude that the measurement of the transfer of learning and the making of rewards contingent upon its transfer, while theoretically crucial, is an extremely difficult exercise and its perceived relevance is thus much reduced.

Furthermore, this study lends some support to the identification of a wider set of transfer factors (Kontoghiorghes, 2004). The identification of training event climate and organizational linkage are worthy of future examination despite the caution expressed in this study around their interpretation.

Although the number of factors studied has been growing (e.g. Cheng \& Hampson, 2008; Kontoghiorghes, 2004; Tews \& Tracey, 2008; Velada \& Caetano, 2007), the current study suggests that practitioners perceive a wider set of factors than is currently examined in research.

\section{Implications}

This research provides an interesting perspective on the issue of transfer of learning from training interventions back into the workplace. The research engages with HRD professionals in Ireland who work closely with management in the design and implementation of learning solutions in organizations today.

From the earliest writings of transfer researchers, there have been references made to training design, learning sequencing and principles of learning (Kontoghiorghes, 2004). Holton identified perceived content validity as the extent to which trainees judge the training content to reflect job requirements accurately (Holton et al., 2000). However, trainer effectiveness has not been identified as an important element in transfer. This omission seems counter-intuitive. The trainer stands in the place of the manager as the principal tutor of the employee as learner, and therefore, it would seem illogical to treat this variable as a constant. We prefer to regard the performance of the trainer as a fluctuating yet critical element in learner performance and postintervention behaviour.

Somewhat controversially, individual rewards were labelled as the least relevant by the respondents. This somewhat surprising result may however be explained in part by the vocation of the respondents and their decision to engage in a profession with the lofty ideals of human development at its core.

\section{Future research}

This research has shown that practitioners perceive relevance in factors that are underresearched in the literature. For example, the issue of trainer effectiveness was perceived by practitioners as being most relevant to transfer and, although the literature has given some attention to the characteristics of the trainer, this may be an area of fruitful research for the future. Organizational linkage and training event climate have received some attention in the literature but are also under-researched. Given the poor results of transfer of training from interventions back into the workplace, it may be useful for researchers to consider how these factors affect the transfer of training. 


\section{Conclusion}

It has been established in the literature that transfer of learning back into the workplace is an important factor explaining why training may not be effective. Accordingly, it is vital that all factors that affect transfer be identified. The search for these factors should draw upon the views of a wide range of relevant stakeholders. This paper researched the views of practitioners, a highly significant stakeholder group, in order to inform the transfer of learning research agenda. Three factors emerged as under-researched, specifically, trainer effectiveness, organizational linkage and training event climate. Further study into these factors may enable a better outcome for transfer of learning.

\section{References}

Al-Khayyat, R. and Eigamal, M. A. (1997), 'A macro model of training and development: validation', Journal of European Industrial Training, 21, 87-101.

Alliger, G. M. and Janak, E. A. (1989), 'Kirkpatrick's levels of training criteria: thirty years later', Personnel Psychology, 42, 331-40.

Alvarez, K., Salas, E. and Garofano, C. M. (2004), 'An integrated model of training evaluation and effectiveness', Human Resource Development Review, 3, 385-416.

Baldwin, T. T. and Ford, J. K. (1988), 'Transfer of training: a review and directions for future research', Personnel Psychology, 41, 63-105.

Barrett, A. and O'Connell, P. (2001), 'Does training generally work? The returns to in-company training', Industrial and Labor Relations Review, 54, 647-62.

Bartlett, M. S. (1954), 'A note on the multiplying factors for various chi square approximations', Journal of the Royal Statistical Society, 16, 296-8.

Bassi, L. J. and Van Buren, M. E. (1999), The 1999 ASTD State of the Industry Report (Alexandria, VA: ASTD).

Bates, R. and Holton, E. F. I. (2004), 'Linking workplace literacy skills and transfer system perceptions', Human Resource Development Quarterly, 15, 153-70.

Bates, R. A., Holton, E. F. I., Seyler, D. L. and Carvalho, M. A. (2000), 'The role of interpersonal factors in the application of computer-based training in an industrial setting', Human Resource Development International, 3, 19-42.

Broad, M. L. and Newstrom, J. W. (1992), Transfer of Training (Reading, MA: Addison-Wesley).

Burke, L. A. and Hutchins, H. M. (2008), 'A study of best practices in training transfer and proposed model of transfer', Human Resource Development Quarterly, 19, 107-28.

Catell, R. B. (1966), 'The scree test for number of factors', Multivariate Behavioral Research, 1, $245-76$.

Cheng, E. W. L. (2000), 'Test of the MBA knowledge and skills transfer', International Journal of Human Resource Management, 11, 837-52.

Cheng, E. W. L. and Hampson, I. (2008), 'Transfer of training: a review and new insights', International Journal of Management Reviews, 10, 327-41.

Chiaburu, D. S. and Lindsay, D. R. (2008), 'Can do or will do? The importance of self-efficacy and instrumentality for training transfer', Human Resource Development International, 11, 199-206.

Chiaburu, D. S. and Marinova, S. V. (2005), 'What predicts skill transfer? An exploratory study of goal orientation, training, self efficacy and organizational supports', International Journal of Training and Development, 9, 110-23.

Chiaburu, D. S. and Tekleab, A. G. (2005), 'Individual and contextual influences on multiple dimensions of training effectiveness', Journal of European Industrial Training, 29, 604-26.

Clark, S. C., Dobbins, H. G. and Ladd, T. R. (1993), 'Exploratory field study of training motivation', Group and Organization Management, 18, 292-307.

Colquitt, J. A., LePine, J. A. and Noe, R. A. (2000), 'Toward an integrative theory of training motivation: a meta-analytic path analysis of 20 years of research', Journal of Applied Psychology, 85, 678-707.

Cromwell, S. E. and Kolb, J. A. (2004), 'An examination of work-environment support factors affecting transfer of supervisory skills training to the workplace', Human Resource Development Quarterly, 15, 449-71.

De Simone, R. L., Werner, J. M. and Harris, D. M. (2002), Human Resource Development (Orlando, FL: Harcourt Inc.).

Fabrigar, L. R., Wegener, D. T., MacCallum, R. C. and Strahan, E. J. (1999), 'Evaluating the use of exploratory factor analysis in psychological research', Psychological Methods, 4, 272-99.

\section{International Journal of Training and Development}


Facteau, J., Dobbins, G., Russell, J., Ladd, R. and Kudisch, J. (1995), 'The influence of general perceptions of the training environment on pretraining motivation and perceived training transfer', Journal of Managment, 21, 1-25.

Ford, J. K. and Weissbein, D. A. (1997), 'Transfer of training: an updated review and analysis', Performance Improvement Quarterly, 10, 22-41.

Gaudine, A. P. and Salks, A. M. (2004), 'A longitudinal quasi-experiment on the effects of posttraining transfer interventions', Human Resource Development Quarterly, 15, 5776.

Gorusch, R. L. (1997), 'Exploratory factor analysis: Its role in item analysis', Journal of Personality Assessment, 68, 532-60.

Green, P. and Skinner, D. (2005), 'Does time management training work? An evaluation', International Journal of Training and Development, 9, 124-39.

Grossman, R. and Salas, E. (2011), 'The transfer of training: what really matters', International Journal of Training and Development, 15, 103-20.

Hofstede, G. (2001), Culture's Consequences: Comparing Values, Behaviours, Institutions and Organisations Across Cultures (Thousand Oaks, CA: Sage Publications).

Holton, E. F. (1996), 'The flawed four-level evaluation model', Human Resource Development Quarterly, 7, 1, 5-21.

Holton, E. F. I. (2005), 'Holton's evaluation model: new evidence and construct elaborations', Advances in Developing Human Resources, 7, 37-54.

Holton, E. F., Bates, R. and Ruona, W. (2000), 'Development of a generalized learning transfer system inventory', Human Resource Development Quarterly, 11, 333-60.

Holton, E. F. I., Hsin-Chih, C. and Naquin, S. S. (2003), 'An examination of learning transfer system characteristics across organizational settings', Human Resource Development Quarterly, 14, 459-82.

Hutchins, H. M. and Burke, L. A. (2007), 'Identifying trainers' knowledge of training transfer research findings - closing the gap between research and practice', International Journal of Training and Development, 11, 236-64.

Kaiser, H. (1970), 'A second generation Little Jiffy', Psychometrika, 35, 401-15.

Kaiser, H. (1974), 'An index of factorial simplicity', Psychometrika, 39, 31-6.

Kaufman, R. (2002), 'Resolving the (often deserved) attacks on training', Performance Improvement, 41, 5-6.

Kirkpatrick, D. L. (1959a), 'Techniques for evaluating training programs', Journal of the American Society of Training Directors, 13, 3-9.

Kirkpatrick, D. L. (1959b), 'Techniques for evaluating training programs - Part 2 - Learning', Journal of the American Society of Training Directors, 13, 21-6.

Kirkpatrick, D. L. (1960a), 'Techniques for evaluating training programs - Part 3 - Behaviour', Journal of the American Society of Training Directors, 14, 13-18.

Kirkpatrick, D. L. (1960b), 'Techniques for evaluating training programs: Part 4 - Results', Journal of the American Society of Training Directors, 14, 28-32.

Kirkpatrick, D. L. (1994), Evaluating Training Programs (San Francisco, CA: Berrett-Koehler).

Kontoghiorghes, C. (2001), 'Factors affecting training effectiveness in the context of the introduction of new technology - a US case study', International Journal of Training and Development, 5, 248-60.

Kontoghiorghes, C. (2002), 'Predicting motivation to learn and motivation to transfer learning back to the job in a service organization: a new systemic model for training effectiveness', Performance Improvement Quarterly, 15, 114-19.

Kontoghiorghes, C. (2004), 'Reconceptualizing the learning transfer conceptual framework: empirical validation of a new systemic model', International Journal of Training and Development, 8, 210-21.

Lim, D. H. and Johnson, S. D. (2002), 'Trainee perceptions of factors that influence learning transfer', International Journal of Training and Development, 6, 36-48.

Mathieu, J., Tannenbaum, S. and Salas, E. (1992), 'Influences of individual and situational characteristics on measures of training effectiveness', Academy of Management Journal, 35, 828-47.

Mathieu, J. E., Martineau, J. W. and Tannenbaum, S. I. (1993), 'Individual and situational influences on the development of self-efficacy: implications for training effectiveness', Personnel Psychology, 46, 125-47.

Montesino, M. U. (2002), 'A descriptive study of some organizational-behavior dimensions at work in the Dominican Republic: Implications for management development and training', Human Resource Development International, 5, 393-410.

Noe, R. A. (2000), 'Invited reaction: development of a generalized learning transfer system inventory', Human Resource Development Quarterly, 11, 361-5. 
Noe, R. A. and Schmitt, N. (1986), 'The influence of trainee attitudes on training effectiveness: test of a model', Personnel Psychology, 39, 497-523.

Rouiller, J. Z. and Goldstein, L. I. (1993), 'The relationship between organizational transfer climate and positive transfer of training', Human Resource Development Quarterly, 4, 377-90.

Ruona, W., Leimbach, M., Holton, E. and Bates, R. (2002), 'The relationship between learner utility reactions and predicted learning transfer among trainees', International Journal of Training and Development, 6, 218-28.

Salas, E. and Cannon-Bowers, J. A. (2001), 'The science of training: a decade of progress', Annual Review of Psychology, 52, 471-99.

Stevens, J. P. (2002), Applied Multivariate Statistics for the Social Sciences (Hillsdale, NJ: Erlbaum Associates).

Subedi, B. S. (2006), 'Cultural factors and beliefs influencing transfer of training', International Journal of Training and Development, 10, 88-97.

Sugrue, B. (2003), State of the Industry. ASTD'S Annual Review of U.S. and International Trends in Workplace Learning and Performance (Alexandria, VA: ASTD).

Tabachnick, B. G. and Fidell, L. S. (2001), Using Multivariate Statistics (Needham Heights, MA: Pearson).

Tannenbaum, S. I. and Yukl, G. (1992), 'Training and development in work organizations', Annual Review of Psychology, 43, 399-441.

Tews, M. J. and Tracey, J. B. (2008), 'An empirical examination of posttraining on-the-job supplements for enhancing the effectiveness of interpersonal skills training', Personnel Psychology, 61, 375-401.

Tharenou, P. (2001), 'The relationship of training motivation to participation in training and development', Journal of Occupational and Organizational Psychology, 74, 599-621.

Thurstone, L. L. (1947), Multiple Factor Analysis (Chicago, IL: University of Chicago Press).

Torraco, R. A. and Swanson, R. A. (1995), 'The strategic roles of human resource development', Human Resource Planning, 18, 10-21.

Tracey, J. B. and Tews, M. J. (2005), 'Construct validity of a general training climate scale', Organizational Research Methods, 8, 353-74.

Tracey, J. B., Tannenbaum, S. I. and Kavanagh, M. J. (1995), 'Applying trained skills on the job: the importance of the work environment', Journal of Applied Psychology, 80, 239-52.

Van der Klink, M., Gielen, E. and Nauta, C. (2001), 'Supervisory support as a major condition to enhance transfer', International Journal of Training and Development, 5, 52-63.

Velada, R. and Caetano, A. (2007), 'Training transfer: the mediating role of perception of learning', Journal of European Industrial Training, 31, 283-96.

Vroom, V. H. (1964), Work and Motivation (New York: Wiley).

Wexley, K. N. and Latham, G. P. (2007), 'Developing and training human resources in organizations', Journal of European Industrial Training, 31, 283-96.

Yamnill, S. and McLean, G. N. (2001), 'Theories supporting the transfer of training', Human Resource Development Quarterly, 12, 195-208. 


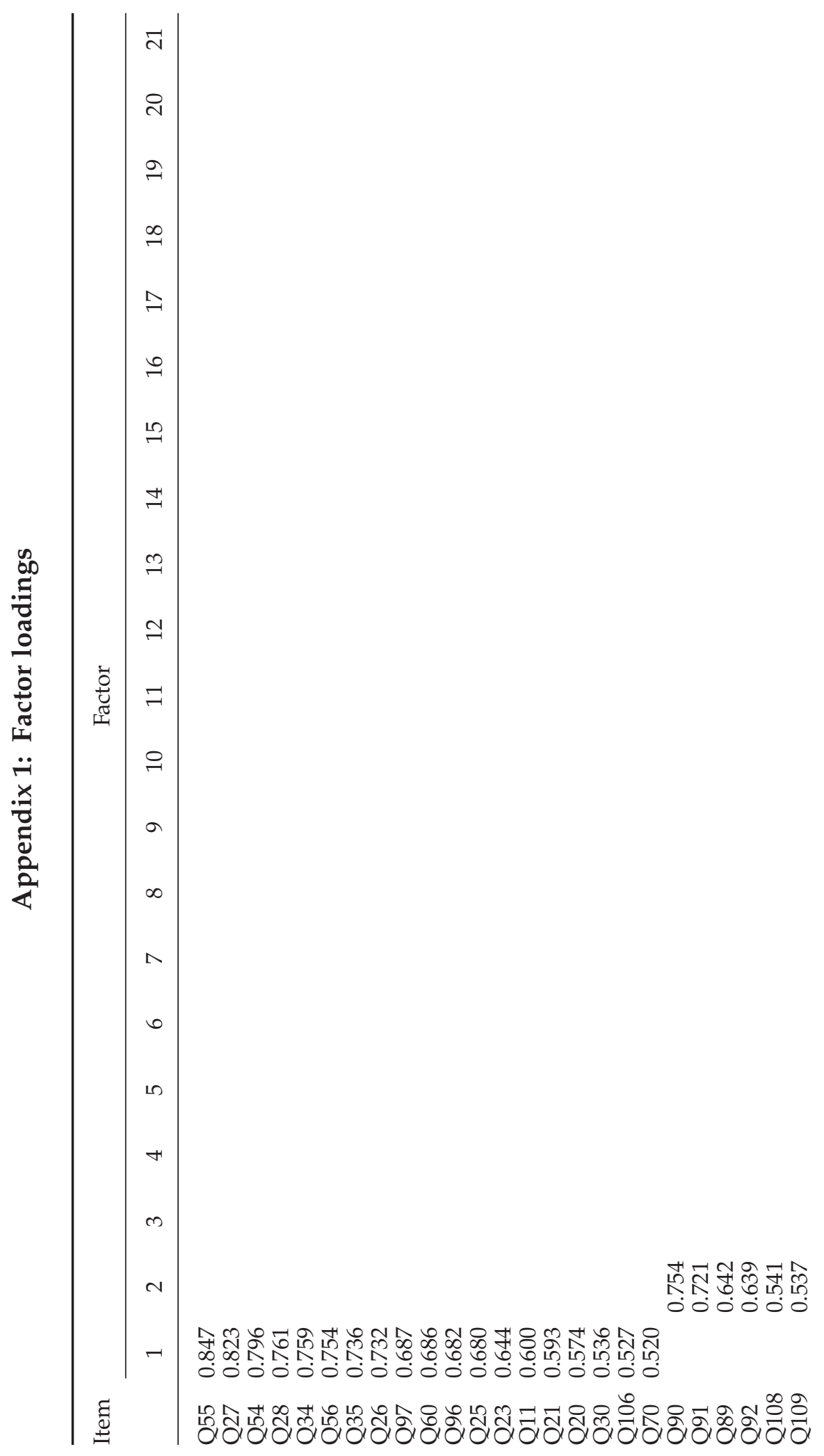

Learning transfer 137 (c) 2011 Blackwell Publishing Ltd. 


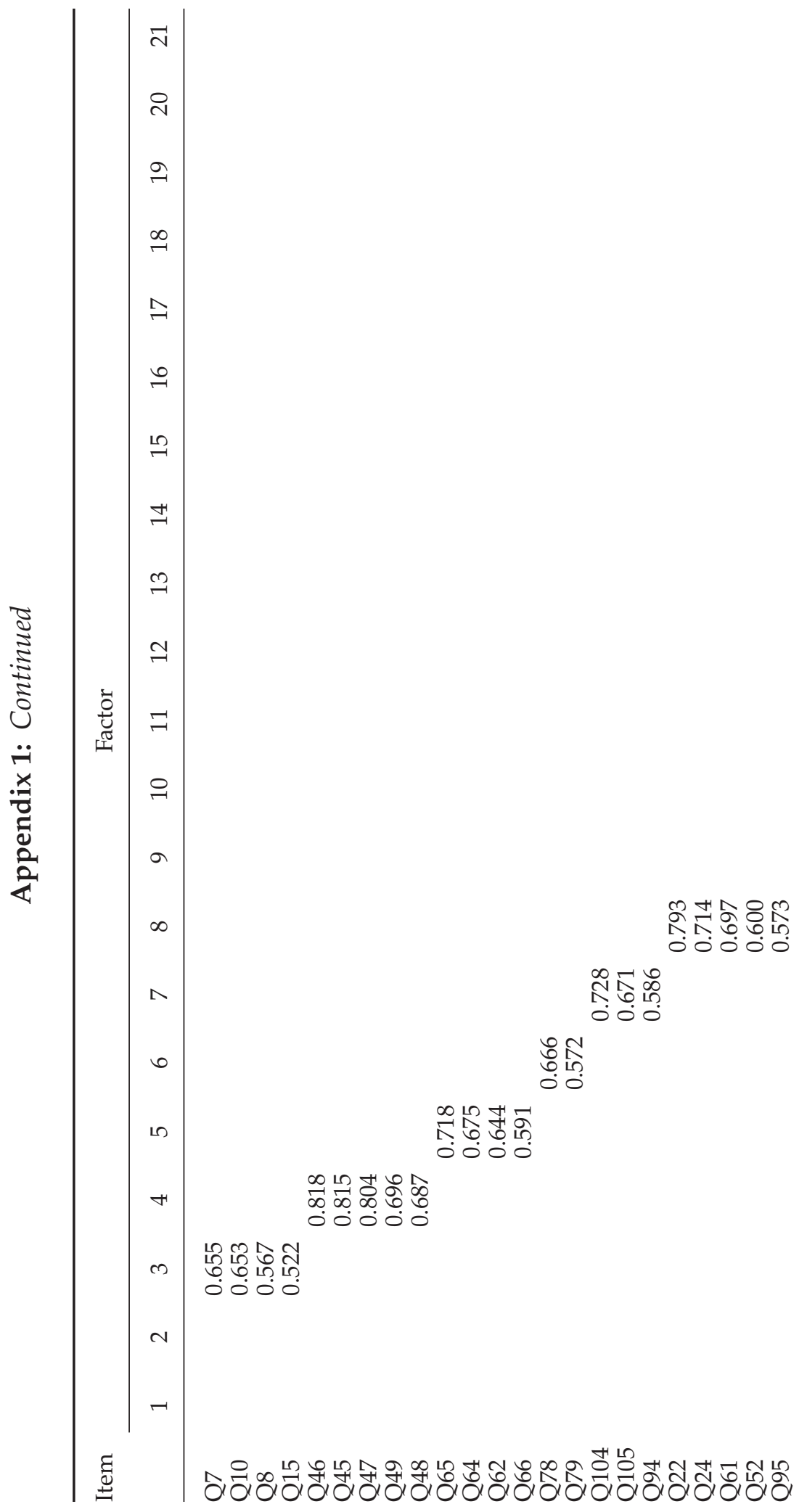

138 International Journal of Training and Development (c) 2011 Blackwell Publishing Ltd. 


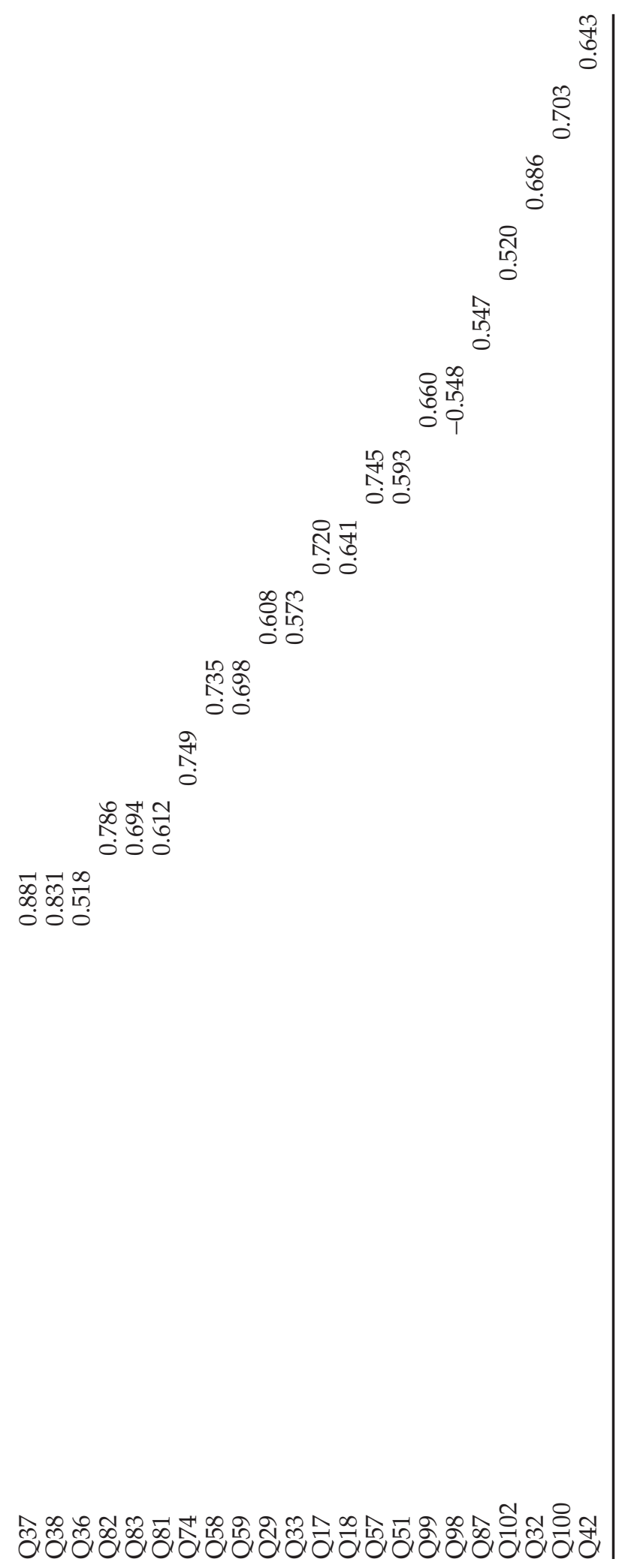

Learning transfer 139 (c) 2011 Blackwell Publishing Ltd. 